\title{
Biological Activities of Stem, Leaves and Essential Oil of Cedrus deodara from District Poonch, Rawalakot Azad Kashmir, Pakistan
}

\author{
Tahir Zaman, Syed Mubashar Sabir*, Sadaf Isfaq, Muhammad Sarfraz Khan
}

Department of Chemistry, University of Poonch, Rawalakot, Azad Kashmir, Pakistan

\begin{tabular}{l} 
A R T I C L E I N F O \\
Research Article \\
Received 26 January 2018 \\
Accepted 08 March 2018 \\
\hline
\end{tabular}

Keywords:

Cedrus deodara

Antioxidant

Iron chelating

Biofilm inhibition

Thrombolytic activity

\begin{abstract}
A B S T R A C T
Cedrus deodara (Roxb. ex D. Don) Loudon, is a high value medicinal plant found in flora of Poonch part of Himalayan region. The present study was conducted to determine and compare the antioxidant activity, quantification of phenolics and flavonoids, chelating ability, biofilm inhibition, thrombolytic activity and cytotoxicity of the stem, leaves of crudes extracts and essential oil. It can be claimed that that all parts of $C$. deodara including its essential oil is a rich source of phytochemicals that exhibited high quantity of phenolics ranged from $(49.76 \pm 0.22 \mathrm{GAE}$ to $60.36 \pm 0.44 \mathrm{GAE} \mathrm{mg} / \mathrm{g})$ and flavonoids ranged from $(4.78 \pm 0.61 \mathrm{mg} / \mathrm{g}$ to $6.62 \pm 0.45 \mathrm{mg} / \mathrm{g})$ but also exhibited antioxidant, metal chelating agent ability, antibacterial potential ranged from $(35.59 \pm 0.50$ to $61.61 \pm 0.61 \%)$ and thrombolytic activities ranged from $(22.86 \pm 0.7$ to $32.64 \pm 0.5 \%)$ with minimal toxicity ranged from $(0.40 \pm 0.35$ to $3.73 \pm 0.23 \%)$. Further studies are required to determine the bioactive compounds and bioactivity of plant extracts and fractions.
\end{abstract}

\footnotetext{
*Corresponding Author:

E-mail: mubashersabir@yahoo.com
}

DOI: https://doi.org/10.24925/turjaf.v6i9.1114-1119.1819

\section{Introduction}

Plants are important to humans' beings not only environmentally, economically and industrially but also spiritually, historically and aesthetically. They sustain human life through numerable tangible and intangible benefits. Now a day at least 120 different types of important drugs containing chemical substances are identified. These chemical substances are derived from plants. These important drugs are used in one or more countries. Some of the drugs are copies of naturally obtained substance. Most of them are simple synthetic modification (Taylor, 2000).

Medicines including high anti biotic and normal syrups were never found a century ago. However, people have been taking different medicines for illness and other health problems. Herbal medicines power cannot be overlooked as prior to all the modern medicines. Even deadly diseases are cured by these herbal medicines. A definite physiologic action on human body is produced by some chemical substances in plants. Alkaloids, flavonoids, tannins and phenolic compounds are most important bioactive compounds (Duraipandiyan et al., 2006). Several authors have reported the in vitro antioxidant activities of plants (Selamoglu et al., 2017; Maria et al., 2014; Dusgun et al., 2015; Selamoglu et al., 2016). Different dietary approaches have been used for the management of free radicals and for the treatment of different health disorders (Badr et al., 2017; Sevindik et al., 2017). Salmas et al. (2017) has reported the protective effect of propolis, caffeic acid and pollen on renal injury in hypertensive rats.

In last fifteen years various aspects of $C$. deodara were explored. In the treatment of remittent and intermittent fevers; diarrhea and dysentery the bark of cedar wood proves to be a good remedy (Nadkarni, 1984). In ulcers treatment the powder of $C$. deodara is used. Cedar wood possesses anti-fungal properties (Nadkarni, 1984). The outer bark and stem of the tree is used to astringent, carminative and antispasmodic and is found in biomedical action of the plant. The digestive function promoted by the Ayurvedic functions of the plant it also removes toxins from the bowel and alleviates coughing. This plant also cures skin disorders, such as eczema. Essential oil of $C$. deodara wood chip was investigated against the diamond back moth which emphasized the study larvicidal activity of $C$. deodara. Ayurvedic medical practice has been carried out since ancient days it was carried out by wood of $C$. deodara (Nadkarni, 1984). C. deodara is also known as Himalayan Cedar.Some activities against house flies and stored pests are found in its essential oil. Flavonoid such as taxifolin, quercetin and 
saponins are the major components of $C$. deodara. Phytosterols of the plant are very effective on hyperlipidemia (Singh et al., 1984). C. deodara also showed a significant anti-spasmodic activity when a $50 \%$ ethanol extract of wood was taken (Vikas et al., 2013). Literature did not quote any studies carried out on the properties of $C$. deodara from Azad Kashmir, Pakistan. Therefore, the objective of present research was to uncover the biological and antioxidant properties of $C$. deodara species for their possible use in food and pharmaceuticals.

\section{Material and Methods}

\section{Collection of Plant Material}

The selection of plant has been on the basis of ethno pharmacologic information and intensive review. Leaves and stem of $C$. deodara have been collected from the high altitude of the Azad Jammu and Kashmir (AJK). It is located at Latitude 3351'32.18" N, Longitude $73^{\circ} 45^{\prime} 34.93^{\prime \prime} \mathrm{E}$ and an Elevation of 5374 feet. Different parts of the plant were collected and identified by a Taxonomist at University of Poonch, Rawalakot AK Pakistan.

\section{Extraction of Essential Oils}

For the extraction the volatile compound from medicinal plant material many analytical methods were used. To extract essential oils hydro distillation method was used. This method is cost effective and simple (Hashemi et al., 2007).

\section{Hydro distillation method}

C. deodara stem and leaves were cut into small pieces. Then these small pieces are air dried in a shady place. These pieces are then immersed in water to carry out hydro distillation (3-5 hours). Clevenger type hydro distillation apparatus was used. Along with the water vapors essential oils were evaporated and condensed in condenser. From aqueous layer the distillate was separated and dried over anhydrous sodium sulphate (Irshad et al., 2012).

\section{DPPH Radical Scavenging Assay}

Scavenging of the stable DPPH radical (ethanolic solution of $0.25 \mathrm{mM}$ ) was assayed in vitro (Hatano et al., 1988) and the absorbance was measured at $517 \mathrm{~nm}$. Percent inhibition was calculated from the control. Ascorbic acid was used as a standard in DPPH assay.

\section{Determination of Phenolics}

The total phenolic content of each plant extract was determined by using the Folin Ciocalteau method (Singleton et al., 1999). Aqueous extracts $(0.5 \mathrm{~mL})$ were added to $2.5 \mathrm{~mL}$ of $10 \%$ Folin ciocalteau's reagent (v/v) and the content was mixed. After 5 minutes $2 \mathrm{~mL}$ of $7.5 \%$ sodium carbonate was added in the mixture. The mixture in the test tube was mixed and allowed for incubation for 40 minutes at $45^{\circ} \mathrm{C}$. The absorbance was measured at 765 nm using a spectrophotometer. Gallic acid will be used as a standard phenol. The concentration of total phenolic is expressed as milligram of Gallic acid/g of mixture. All the determinations were carried out in triplicate.

\section{Determination of Flavonoids}

Total flavonoid content was determined using aluminium chloride. The total flavonoid content as quercetin equivalents was determined (Kosalecet al., 2004). Quercetin was used to construct calibration curves. Standard solutions or extracts $(0.5 \mathrm{~mL})$ was mixed with $1.5 \mathrm{~mL}$ of $95 \%$ ethanol $(\mathrm{v} / \mathrm{v}), 0.1 \mathrm{~mL}$ of $10 \%$ aluminium chloride (w/v), $0.1 \mathrm{~mL}$ of $1 \mathrm{~mol} / \mathrm{L}$ sodium acetate and $2.8 \mathrm{~mL}$ of water. The volume of $10 \%$ aluminium chloride will be replaced using the same volume of distilled water for use as a blank.

\section{Metal Chelating Activity}

The iron chelating ability of the extractwas determined using a modified method (Puntel et al., 2005).

Biofilm inhibition assay (By microtitre-plate method): Bacterial strain Escherichia coli was obtained and cultivated at $37^{\circ} \mathrm{C}$ and maintained on nutrient agar slant at $4^{\circ} \mathrm{C}$. The wells of a sterile 96 -well flat bottomed plastic tissue culture plate were filled with $100 \mathrm{uL}$ of nutrient broth (Oxford, UK), $100 \mathrm{uL}$ of testing sample and $20 \mathrm{uL}$ of bacterial suspension inoculated. Nutrient broth was taken as negative control only, while a standard chemical synthetic drug Rifampicin was taken as positive control. At $37^{\circ} \mathrm{C}$ for 24 hours these plates were covered and incubated aerobically. With $220 \mathrm{uL}$ of sterile phosphate buffer the content of each well was washed thrice. In order to remove all non-adherent bacteria, the plates were vigorously shaken. With 220 microlitres of $99 \%$ methanol per well, the remaining attached bacteria were fixed and after 15 min plates were emptied and left to dry. Then, plates were stained for 5 min with $220 \mathrm{~mL}$ of $50 \%$ crystal violet per well. By placing the plates under running tap water, the excess stain was rinsed off. After the plates were dried after that with $220 \mu$ Lof $33 \%$ (v/v) glacial acetic acid per well the bounded adherent than air dried dye was re solubilized. At $630 \mathrm{~nm}$ using microplate reader, the OD of each well was measured (BioTek, USA). All the tests were carried thrice times against both selected bacterial strain and the results were averaged (Shahid et al., 2015).

The bacterial growth inhibition (INH\%) was calculated as follows:

$$
I N H \%=100-\left(O D_{630 \text { sample }} \times 100\right) / O D_{630 \text { control }}
$$

\section{Thrombolytic Activity}

Five different pre-weighed sterile micro centrifuge tube were used to take $5 \mathrm{~mL}$ of venous blood from each volunteer and permitted to incubate at $37^{\circ} \mathrm{C}$ for $40 \mathrm{~min}$. From each centrifuge tube, the fluid was completely released after clot formation and the clot weight was determined by subtracting weight of clot containing tube from weight of tube alone. To the centrifuge tube s $100 \mathrm{uL}$ of each sample were added separately, streptokinase and distilled water $(100 \mathrm{uL})$ were taken as positive and negative control respectively. For almost an hour at room temperature these test tubes were incubated and observed for clot lysis. The released fluid was discarded after incubation and tubes were again weighed to assess the differences in weight after clot disruption ((Prasad et al., 2007)). By following formula, the percentage of clot lysis was determined.

Percent of clot lysis $=($ wt of released clot $/$ clot wt $) \times 100$ 
Cytotoxicity (Hemolytic Activity): Fresh heparinized bovine blood $(3 \mathrm{~mL})$ was collected from Department of Clinical Medicine and Surgery, University of Agriculture, Faisalabad, Pakistan. For $5 \mathrm{~min}$ at $1000 \times \mathrm{g}$ the blood was centrifuged, and the plasma obtained was discarded while the cells were washed thrice with $5 \mathrm{~mL}$ chilled $\left(40^{\circ} \mathrm{C}\right)$ sterile isotonic Phosphate-buffered saline at $\mathrm{pH}$ 7.4. For each assay erythrocytes were maintained 108 cells per $\mathrm{mL}$. Each compound of $100 \mathrm{uL}$ was mixed with human (108cells/mL) separately. At room temperature these samples were incubated and agitated satisfactorily after 10 min. These samples were placed over an ice berg immediately after incubation followed by centrifugation for $5 \mathrm{~min}$ at $1000 \times \mathrm{g}$. From each tube the supernatant of $100 \mathrm{uL}$ was taken and diluted 10 times with chilled Phosphate-buffered saline (PBS). PBS was taken negative control while the Triton $\mathrm{X}-100$ was taken as positive control and pass through the same process at $760 \mathrm{~nm}$ the absorbance was noted using Quant (BIiotech, USA). The calculation was made at the end for percent RBCs lysis for each sample (Shabbir et al., 2015)

\section{Data Analysis}

The results were expressed as means \pm SD. The data were analyzed by one-way ANOVA and different group means were compared by applying Duncan's multiple range test $(\mathrm{DMRT}) ; \mathrm{P}<0.05$ was considered significant in all cases. The software package, Statistica was used for statistical analysis

\section{Results}

\section{DPPH Radical Scavenging Activity}

The entire extracts under study were analysed by free radical scavenging activity by the DPPH method. The antioxidant activity of extracts was found to dependent upon the concentration which is shown in the Table 1. There is the difference in the activity of the different parts of plants. It is cleared from the results that all the extracts have significant antioxidant potential. The strong scavenging activity was shown by the leaves of $C$. deodara. Total antioxidant activity of the leave extracts of the $C$. deodara is lower than the stem but more than other plants extracts. Leaves extract showed IC50 value of 28.16 .

\section{Phenolic and Flavonoids Content}

In the present study the phenolic compounds in the different parts of the plant $C$. deodara were analysed. The total phenolic content was taken as milligram of gallic acid per gram of the extracts. The results are shown in Table 2. The highest phenolic contents were detected in the essential oils of leaves and wood of $C$. deodara $(49.76 \pm 0.22 \mathrm{GAE} \mathrm{mg} / \mathrm{g})$ and $(60.36 \pm 0.44 \mathrm{GAE} \mathrm{mg} / \mathrm{g})$ respectively among all the tested results. The stemof these plants were found to be comparatively higher in phenolic contents than the leaves. On the other hand flavonoid content ranged from $4.78 \pm 0.61 \mathrm{mg} / \mathrm{g}$ to $6.62 \pm 0.45 \mathrm{mg} / \mathrm{g}$ for stem and leaves in methanolic extract respectively, while essential oil have $6.62 \pm 0.45 \mathrm{mg} / \mathrm{g}$ of flavonoid content (Table 2). It was also concluded that antioxidant activity has the strong relation with the total phenolic $\left(\mathrm{R}^{2}=0.72\right)$ and flavonoids $\left(\mathrm{R}^{2}=0.816\right)$ contents.

\section{Metal Chelation}

The results showed that the $C$. deodara was found to show the high chelating ability (Table 3 ). Increasing the concentration of the extracts chelating ability also increased. Our results showed that the maximum chelating ability is shown by the essential oil than the normal extract both in stem and leaves of the $C$. deodara.

\section{Biofilm Inhibition by Microtitre-Plate Method}

C. deodara methanlic extracts of leaves and stem and their respective oil were subjected for biofilm inhibitory assay shown in Table 4. Rifampicin was taken as standard inhibitory drug which showed highest percentage inhibitory effect of $95.08 \pm 0.65$. The percentage inhibition ranged from $35.59 \pm 0.50$ to $61.61 \pm 0.61$ for $C$. deodara leaves methanolic extract to stem essential oil, while the methanolic extract of stem and essential oil of the leaves also showed considerable percentage inhibition $(42.18 \pm 0.71 \%$ and $45.74 \pm 0.54 \%)$ respectively. The ascending order of percentage inhibition by taking Rifampicin as standard is as CdL (leaves) $<\mathrm{CdM}$ (stem) $<$ CdLEO (leaf oil) <CdSEO (stem oil) <Rafampicin.

Table 1 Percentage DPPH scavenging activity of the leave and stem extracts of the Cedrus deodara

\begin{tabular}{l|cc}
\hline Concentration of extracts $\mu \mathrm{g} / \mathrm{ml}$ & Percentage scavenging by leaves extracts & Percentage scavenging by stem extracts \\
\hline 25 & $44.38 \pm 0.36$ & $54.16 \pm 0.41$ \\
50 & $34.17 \pm 0.085$ & $61.48 \pm 0.43$ \\
75 & $29.88 \pm 0.1$ & $66.48 \pm 0.45$ \\
100 & $22.83 \pm 0.13$ & $69.16 \pm 0.86$ \\
200 & $15.13 \pm 0.514$ & $70.18 \pm 0.52$ \\
\hline
\end{tabular}

Table 2 Total Phenolic and flavonoids contents of methanolic extracts of the plants, stem and leaves

\begin{tabular}{l|cc}
\hline \multicolumn{1}{c|}{ Plants } & Phenolic content (mg GAE/g extract) & Flavonoids content (mg /g extract) \\
\hline Cd LME & $23.95 \pm 0.48^{\mathrm{a}}$ & $5.56 \pm 0.55^{\mathrm{a}}$ \\
Cd SME & $28.16 \pm 0.55^{\mathrm{b}}$ & $4.78 \pm 0.61^{\mathrm{b}}$ \\
Cd LEO & $49.76 \pm 0.22^{\mathrm{c}}$ & $6.62 \pm 0.45^{\mathrm{c}}$ \\
Cd SEO & $60.36 \pm 0.44^{\mathrm{d}}$ & $6.48 \pm, 0.44^{\mathrm{d}}$ \\
\hline
\end{tabular}

Values in Table which share different letters are significantly $(\mathrm{P}<0.05)$ different from each other by DMRT.CD= Cedrus deodara LME=leaves methanolic extract, $\mathrm{SME}=$ stem methanolic extract $\mathrm{LEO}=$ Leave essential oil, SEO=Stem essential oil 
Table 3 Metal Chelation by methanolic extracts of Cedrus deodara leaves and stems and their essential oils

\begin{tabular}{l|cccc}
\hline $\begin{array}{c}\text { Concentration of } \\
\text { extracts } \mu \mathrm{g} / \mathrm{ml}\end{array}$ & $\begin{array}{c}\text { Percentage Chelation } \\
\text { by leaves extracts }\end{array}$ & $\begin{array}{c}\text { Percentage chelation } \\
\text { by stem extracts }\end{array}$ & $\begin{array}{c}\text { Percentage chelation } \\
\text { by leaves essential oil }\end{array}$ & $\begin{array}{c}\text { Percentage chelation } \\
\text { by stem essential oil }\end{array}$ \\
\hline 25 & $28.50 \pm 0.53$ & $34.72 \pm 0.72$ & $37.59 \pm 0.65$ & $34.64 \pm 0.83$ \\
50 & $42.95 \pm 0.6$ & $46.77 \pm 0.75$ & $34.88 \pm 0.6$ & $38.91 \pm 0.85$ \\
75 & $46.68 \pm 0.58$ & $52.82 \pm 0.59$ & $48.84 \pm 0.6$ & $46.58 \pm 0.41$ \\
100 & $58.76 \pm 0.5$ & $61.13 \pm 0.51$ & $62.86 \pm 0.8$ & $67.68 \pm 0.89$ \\
\hline
\end{tabular}

Table 4 Biofilm inhibition assay by microtitre-plate method of different parts of Cedrus deodara

\begin{tabular}{l|c}
\multicolumn{1}{c|}{ Sample name } & Biofilm Inhibition against E.coli $(\%)$ \\
\hline Cd leaves & $35.59 \pm 0.50^{\mathrm{a}}$ \\
Cd Stem & $42.18 \pm 0.71^{\mathrm{b}}$ \\
Cd LEO & $45.74 \pm 0.54^{\mathrm{c}}$ \\
Cd SEO & $61.61 \pm 0.61^{\mathrm{d}}$ \\
Rifampicin & $95.08 \pm 0.65^{\mathrm{e}}$ \\
\hline
\end{tabular}

$\mathrm{CD}=$ Cedrus deodara $\mathrm{LEO}=$ Leave essential oil, $\mathrm{SEO}=$ Stem essential oil, Values in Table which share different letters are significantly $(\mathrm{P}<0.05)$ different from each other by DMRT.

Table 5 Thrombolytic activities of different parts of Cedrus deodara

\begin{tabular}{l|c}
\multicolumn{1}{c|}{ Sample Name } & Thrombolytic Activity (\%) \\
\hline Cd Leaves & $23.79 \pm 0.5^{\mathrm{a}}$ \\
Cd Stem & $22.86 \pm 0.7^{\mathrm{b}}$ \\
Cd LEO & $32.64 \pm 0.5^{\mathrm{c}}$ \\
Cd STO & $30.95 \pm 1.24^{\mathrm{d}}$ \\
Streptokinase & $89.85 \pm 0.36^{\mathrm{e}}$ \\
Distilled Water & $2.59 \pm 0.52^{\mathrm{f}}$ \\
\hline
\end{tabular}

PBS =Phosphate Buffer Saline, $\mathrm{CD}=$ Cedrus deodara $\mathrm{LEO}=$ Leave essential oil, STO=Stem essential oil, Values in Table which share different letters are significantly $(\mathrm{P}<0.05)$ different from each other by DMRT.

Table 6 Cytotoxicity by hemolytic activity of different parts of Cedrus deodara

\begin{tabular}{l|c}
\multicolumn{1}{c}{ Sample Name } & Cytotoxicity (\%) by Hemolytic activity \\
\hline$C d$ Leaves & $0.81 \pm 0.09^{\mathrm{a}}$ \\
$C d$ Stem & $3.73 \pm 0.23^{\mathrm{b}}$ \\
Cd LEO & $0.406 \pm 0.35^{\mathrm{c}}$ \\
$C d$ SEO & $1.443 \pm 0.47^{\mathrm{d}}$ \\
Trition-X 100 & $97.70 \pm 0.50^{\mathrm{e}}$ \\
PBS & $1.61 \pm 0.51^{\mathrm{f}}$ \\
\hline
\end{tabular}

Values in Table which share different letters are significantly $(\mathrm{P}<0.05)$ different from each other by DMRT.

\section{Thrombolytic Activity}

The ability to breakdown the blood clot formed was detected for all the four subjects while taking streptokinase and distilled water as positive and negative control (89.85 \pm 0.36 and $2.59 \pm 0.52(\%)$ thrombolytic activity respectively (Table 5). The percentage thrombolytic ability of $C$. deodara ranged from $22.86 \pm 0.7$ to $32.64 \pm 0.5(\%)$ thrombolytic activity for methanolic extract of stem to essential oil of leaves. The essential oil of stem part and leaves only also showed considerable ability to lyse the blood clot which were $30.95 \pm 1.24$ and $23.79 \pm 0.5 \%$ respectively. For the first time these activities were determined for $C$. deodara which may lead to isolation of some useful thrombolytic drug.

\section{Cytotoxicity of Extracts}

For positive control of experiment Triton X-100 (0.1\% $\mathrm{v} / \mathrm{v})$ was taken $(97.70 \pm 0.50 \quad(\%)$ Cytotoxicity). The phosphate buffer saline (PBS) was taken as negative control $(1.61 \pm 0.51(\%)$. Cytotoxicity $(\%)$ by hemolytic activities for various parts were analysed (Table 6). The percentage cytotoxicity ranged from $0.406 \pm 0.35$ to $3.73 \pm 0.23(\%)$ for essential oil of leaves of C.deodara to stem of the Cedrus deodara. Leaves and its essential oil also showed minimal cytotoxicity $0.81 \pm 0.09$ and $1.443 \pm 0.47(\%)$ respectively. As a whole stem contains higher cytotoxicity than leaves parts.

\section{Discussion}

There is no significant correlation between the antioxidant activity and the phenolic compounds in some of the extracts. The antioxidant activity is not only related with the phenolic content but also have the relation with the other free radical scavenges (Ozgen et al., 2006). Here the antioxidant activity showed a strong correlation with phenolic and flavonoid content. Ozgen et al., (2016) have reported the antioxidant activities of flavonoids such as Quercetin. Polyphenolic compouns have several health protective properties (Selamoglu, 2017, Sevindik et al., 2017). Phenolic compounds are the important class of the antioxidants and are termed as free radical terminators. Flavonoids exhibit a broad range of activities including the anticancer activities (Selamoglu, 2017).

The total phenolic content was estimated by the Folin Ciocalteo reagent and expressed as gallic acid 
equivalents. The present study revealed that the stem of the $C$. deodara have high phenolic content than the leaves. They play important role in the defence mechanism against endogenous and exogenous free radicals (Shad et al.,2013). Total antioxidant activity of the leave extracts of the C. deodara is lower than the stem but more than other plants extracts. One more study revealed that methanolic extracts of the $C$. deodara have more antioxidant potential than their aqueous extracts. Antioxidant potential is related with the reducing power, scavenging power and total phenolic contents (Ozgen et al., 2006). Several authors have reported the health beneficial effect of medicinal plants (Amin et al., 2018; Amin et al., 2017).

The $C$. deodara in the present study was found to show the high chelating ability against iron. Increasing the concentration of the extracts chelating ability also increased. Our results showed that the maximum chelating ability is shown by the essential oil than the normal extract both in stem and leaves of the $C$. deodara. The ability to chelate the metal ions is due to the presence of polyphenols and flavonoids. It was found that $M$. ravens extracts interfere with the most active metal iron and shown the chelation activity of 80 percent. Alzheimer's syndrome which is a neurological disorder and many other diseases caused by the ferrous ions. It is chelated and reduces the formation of the ROS (Ebrahimzadeh et al., 2008). For the toxic metals chelation many types of metal chelators are available. But it is very difficult the selection of the chelator as an ideal chelator. Metal chelators should be specific and proper administration (Flora et al., 2010). Natural plants contain the phytochemical such as phenols and flavonoid which are responsible for the chelation of the metals and also prevent the lipid peroxidation (Jayaprakasha and Patil, 2007).

On testing bases only one type of bacterium was selected to test the various methanolic extracts (stem and leaves) and its essential oil was subjected to biofilm inhibition assay. On the basis of results Table 4 showed that exhibited a significant antibacterial effect against Gram negative bacteria called E.coli particularly. As compare to planktonic form bacteria in biofilm have been shown to be much more resistant to antibiotics (Lewis, 2001). The success of natural compounds in inhibiting cell attachment is a promising tool for reducing microbial colonization on various surfaces (Bavington and Page, 2005). How to prevent microbial infections is a interesting approach which made the large implications of anti-adhesion agents (Ofek et al., 2003; Steinberg et al., 2004).

In order to find a natural compound able to inhibit and prevent microbial biofilm formation, we tested the effect of methanolic extracts and oil on biofilm E. coli strains. Crystal violet assay showed that methanolic extracts and their oil reduce the number of adherent bacteria.

Our results revealed that various extracts of $C$. deodara efficiently kills E.coli suspension and prevent biofilm formation. By microscopic analysis of strains grown on the surface of glass slides covers the effect on biofilm formation was confirmed. We observed a biofilm inhibition when we inoculated the strain with a particular concentration.
The result of this work showed that the methanolic extracts (leaves and stem) and their respective oil had mild to moderate to thrombolytic activity (Table 5). The results of clot lysis were indicated that test samples showed different thrombolytic activity. The significant average percent of clot lysis $(32.64 \pm 0.53$ and $30.95 \pm 1.24)$ of leaves and stem essential oil of $C$. deodara was found. Therefore, it is evident that the essential oil sample and methanolic extract were thrombolytic. As a positive control streptokinase (SK), a known thrombolytic drug is used while distilled water as negative control (Prasad et al., 2007). The comparison of positive control with negative control clearly confirmed that clot dissolution does not occur when water was added to the clot. By comparing with this positive and negative control, a significant thrombolytic activity was observed after treating the clots with essential oil and methanolic leaves and stem extracts.

Drugs either purified or crude must be screened for safe usage that's the reason why cytotoxicity assays are widely used by the pharmaceutical industries. Before investing in their development as a pharmaceutical drug, cytotoxic compounds can either look for researchers, if they are interested in developing a therapeutic that targets rapidly dividing cancer cells, for instance; or they can screen "hits" from initial high-throughput drug screens for unwanted cytotoxic effects. To kill rapidly growing cancerous cells is solely depends upon the cytotoxicity ability and also depends upon the concentration of compound(s) in the sample (Svensson et al., 2005). Cytotoxic results indicated that test samples have low toxicity and they can be recommended for human and animal consumption.

\section{Conclusions}

it can be claimed that that all parts of C.deodara including its essential oil is a rich source of phytochemicals that exhibited high quantity of phenolics and flavonoids but also exhibited antioxidant, metal chelating agent, antibacterial and thrombolytic activities with minimal toxicity. Hence, further studies are suggested to be undertaken to pin point the exact compounds and to better, understand its actions scientifically.

\section{Conflict of Interest Statement}

The authors declare no conflict of interest.

\section{Acknowledgement}

We are thankful to the Department of Chemistry, University of Poonch, Rawalakot, A.K. Pakistan to provide the necessary funds to carry out this research.

\section{References}

Amin K, Ozgen S, Selamoglu Z. 2018. Aloe Vera: A Miracle Plant with its Wide-Ranging Applications. Pharm Pharmacol Int J 6(1): 00144. DOI: 10.15406/ppij.2017.06.00144.

Amin K, Ozgen S , Selamoglu Z. 2017. Stevia Rebaudiana: A Potential Boon for human health. SM J Med Plant Studies. 1(1): 1005. 
Badr G, Ramadan N, Sayed L, Omar H, Badr BD, Selamoglu Z. 2017. Why whey? Camel whey protein as a new dietary approach for the management of free radicals and for the treatment of different health disorders. Iran J Basic Med Sci 20 (4): 338-349.

Bavington C, Page C. 2005. Stopping bacterial adhesion: a novel approach to treating infections. Respiration 72(4): 335-344.

Duraipandiyan V, Ayyanar M, Ignacimuthu S. 2006. Antimicrobial activity of some ethnomedicinal plants used by Paliyar tribe from Tamil Nadu, India. BMC Complement Altern Med 6: 35.

Dusgun C, Gulhan MF, Duruyurek M, Selamoglu Z, Erdemli ME. 2015. In vitro Analyses of Antioxidant Activity of Extracts of Some Selected Plants from Nigde, Turkey. EDUCA, “casopis za obrazovanje, nauku i kulturu. Godina VIII, br. 8. 3-11, Mostar, September 2015.

Ebrahimzadeh MA, Pourmorad F, Bekhradnia AR. 2008. Iron chelating activity, phenol and flavonoid content of some medicinal plants from Iran. Afr J Biotech.7: 3188-3192.

Hashemi P, Abolghasemi M, Fakhari A, Ebrahimi SN, Ahmadi S. 2007. Hydrodistillation-solvent microextraction and GCMS identification of volatile components of Artemisia aucheri. Chromatographia 66(3-4): 283-286.

Hussain S, AliS, Shahzadi S, Rizzoli C, Shahid M. 2015. Diorganotin (IV) Complexes with Monohydrate Disodium Salt of Iminodiacetic Acid: Synthesis, Characterization, Crystal Structure and Biological Activities. J Chinese Chem Soc62(9): 793-802.

Hussain S, Ali S, Shahzadi S, Rizzoli C, Shahid M. 2015. Diorganotin (IV) Complexes with Monohydrate Disodium Salt of Iminodiacetic Acid: Synthesis, Characterization, Crystal Structure and Biological Activities.J Chinese Chem Soc 62(9): 793-802.

HatanoT, Kagawa H, Yasuhara T, Okuda T.1988. Two new flavonoids and other constituents in licorice root; their relative astringency and radical scavenging effects. Chem PharmBull 36: 2090-2097.

Irshad M, Aziz S, Shahid M, Ahmed MN, Minhas FA, Sherazi T. 2012. Antioxidant and antimicrobial activities of essential oil of Skimmea laureola growing wild in the State of Jammu and Kashmir. J Med Plants Res6(9): 1680-1684.

Jayaprakasha G, Patil BS. 2007. In vitro evaluation of the antioxidant activities in fruit extracts from citron and blood orange. Food Chem 101(1): 410-418.

Kosalec I, Bakmaz M, Pepeliniak S, Vladimir-Knezevic S. 2004. Quantitative analysis of the flavonoids in raw propolis from northern Croatia. Acta Pharm 54: 65-72.

Maria D, Lorenzo AD, Nabavi SF, Selamoglu ZT, Nabavi SM. 2014. Polyphenols: well beyond the antioxidant capacity: gallic acid and related compounds as neuroprotective agents: you are what you eat! Curr Pharm Biotech 15: 362-372.

Nadkarni NM. 1986. The nutritional effects of epiphytes on host trees with special reference to alteration of precipitation chemistry. Selbyana 9: 44-51.

Ofek I, Hasty DL, Sharon N. 2003. Anti-adhesion therapy of bacterial diseases: prospects and problems. FEMS.Immunol Med Microbiol 38(3): 181-191.

Ozgen M, Reese RN, Tulio AZ, Scheerens JC, Miller AR. 2006. Modified 2, 2-azino-bis-3-ethylbenzothiazoline-6-sulfonic acid (ABTS) method to measure antioxidant capacity of selected small fruits and comparison to ferric reducing antioxidant power (FRAP) and 2, 2'-diphenyl-1picrylhydrazyl (DPPH) methods. J Agric Food Chem 54(4): 1151-1157.

Ozgen S, Kilinc OK, Z, Selamoglu Z. 2016. Antioxidant Activity of Quercetin: A Mechanistic Review. TURJAF 4(12): 1134-1138.
Prasad S, Kashyap RS, Deopujari JY, Purohit HJ, Taori GM, Daginawala HF. 2007. Effect of Fagonia arabica (Dhamasa) on in vitro thrombolysis. BMC Complement Altern Med 7: 36.

Puntel RL, Nogueira CW, Rocha JBT. 2005. Krebs cycle intermediates modulate thiobarbituric acid reactive species (TBARS) production in rat brain in vitro. Neurochem Res 30: 225-235.

Robu S, Aprotosoaie AC, Miron A, Cioancă O, Stănescu U, Hăncianu M. 2012. In vitro antioxidant activity of ethanolic extracts from some Lavandula species cultivated in Romania. Farmacia 60(3): 394-401.

Selamoglu Z, Dusgun C, Akgul H, Gulhan MF. 2017. In vitro Antioxidant Activities of the Ethanolic Extracts of Some Contained-Allantoin Plants. Iran J Pharm 15: 92-98.

Selamoglu Z, Ustuntas HE, Ozgen S. 2016. Traditional and Complementary Alternative Medicine Practices of some Aromatic Plants in the Human Health. Res J Biol 4 (2): 5254.

Selamoglu Z, 2017. Polyphenolic Compounds in Human Health with Pharmacological Properties. J Trad Med Clin Naturopathy 6(4): 37.

Sevindik M, Akgul H, Pehlivan M, Selamoglu Z. 2017. Determination of Therapeutic Potential of Mentha longifolia Ssp. Longifolia. Fresenius Envir Bull. 26(7) : 4757-4763.

Sevindik M, Akgül H, Akata I, Selamoğlu Z. 2017. Geastrum Pectinatum as an Alternative Antioxidant Source with some Biochemical Analysis. Med Mycol 3(2:25): 2471-8521.

Salmas RE, Gulhan MF, Durdagi S, Sahna E, Abdullah HI, Selamoglu Z. 2017. Effects of Propolis, Caffeic Acid Phenethyl Ester and Pollen on Renal Injury in Hypertensive Rat: An Experimental and Theoretical Approach. Cell Biochem Funct Doi :10.1002/cbf.3277.

Selamoglu Z. 2017. Biotechnological Approaches on Anticancer Activity of Flavonoids. Mod Appro Drug Des. 1(2). MADD.000510.

Shad M, Nawaz H, Rehman T, Ikram N. 2013. Determination of some biochemicals, phytochemicals and antioxidant properties of different parts of Cichorium intybus L. A comparative study. J Anim Plant Sci 23(4): 1060-1066.

Shahid SA, Anwar F, Shahid M, Majeed N, Azam A, Bashir M, Shakir I. 2015. Laser-Assisted synthesis of Mn 0.50 Zn 0.50 $\mathrm{Fe}_{2} \mathrm{O}_{4}$ nanomaterial: characterization and in vitro inhibition activity towards bacillus subtilis biofilm. J Nanomater 2015: 1-6.

Singh D, Rao S, Tripathi A. 1984. Cedarwood oil as a potential insecticidal agent against mosquitoes. Naturwissenschaften 71(5): 265-266.

Singleton VL, Orthofer R, Lamuela-Raventos RM. 1999. Analysis of total phenols and other oxidation substrates and antioxidants by means of folin-ciocalteu reagent. Methods Enzymol 299: 152-178.

Steinberg D, Feldman M, Ofek I, Weiss EI. 2004. Effect of a high-molecular-weight component of cranberry on constituents of dental biofilm. J antimicrob Chemother 54(1): 86-89.

Svensson BM. 2007. Methodology for evaluation of hazards from solid waste and landfill-generated leachate. Int $\mathbf{J}$ Environ Anal Chem 2007: 1-15.

Takao T, Kitatani F, Watanabe N, Yagi A, Sakata K. 1994. A simple screening method for antioxidants and isolation of several antioxidants produced by marine bacteria from fish and shellfish. BiosciBiotechBiochem 58(10): 1780-1783.

Vikas S, Dhar K, Pooja S, Parul S.2013. Indian herbal medicineA natural cure to asthma. Int. J. of Pharmacog. Phytochem Res 14: 302-310. 